\title{
The association of maternal polyunsaturated fatty acids during pregnancy with social competence and problem behaviours at 7 years of age
}

Citation for published version (APA):

Tore, E. C., Gielen, M., Antoniou, E. E., de Groot, R. H. M., Godschalk, R. W. L., Southwood, T. R., Smits, L., Stratakis, N., van de Wurff, I. S. M., \& Zeegers, M. P. (2019). The association of maternal polyunsaturated fatty acids during pregnancy with social competence and problem behaviours at 7 years of age: The MEFAB cohort. Prostaglandins Leukotrienes and Essential Fatty Acids, 144, 1-9. https://doi.org/10.1016/j.plefa.2019.04.002

Document status and date:

Published: 01/05/2019

DOI:

10.1016/j.plefa.2019.04.002

Document Version:

Publisher's PDF, also known as Version of record

Document license:

Taverne

Please check the document version of this publication:

- A submitted manuscript is the version of the article upon submission and before peer-review. There can be important differences between the submitted version and the official published version of record.

People interested in the research are advised to contact the author for the final version of the publication, or visit the DOI to the publisher's website.

- The final author version and the galley proof are versions of the publication after peer review.

- The final published version features the final layout of the paper including the volume, issue and page numbers.

Link to publication

\footnotetext{
General rights rights.

- You may freely distribute the URL identifying the publication in the public portal. please follow below link for the End User Agreement:

www.umlib.nl/taverne-license

Take down policy

If you believe that this document breaches copyright please contact us at:

repository@maastrichtuniversity.nl

providing details and we will investigate your claim.
}

Copyright and moral rights for the publications made accessible in the public portal are retained by the authors and/or other copyright owners and it is a condition of accessing publications that users recognise and abide by the legal requirements associated with these

- Users may download and print one copy of any publication from the public portal for the purpose of private study or research.

- You may not further distribute the material or use it for any profit-making activity or commercial gain

If the publication is distributed under the terms of Article $25 \mathrm{fa}$ of the Dutch Copyright Act, indicated by the "Taverne" license above, 
Original research article

\title{
The association of maternal polyunsaturated fatty acids during pregnancy with social competence and problem behaviours at 7 years of age: The MEFAB cohort
}

\author{
E.C. Tore ${ }^{\mathrm{a}, \mathrm{b}, *}$, M. Gielen ${ }^{\mathrm{c}}$, E.E. Antoniou ${ }^{\mathrm{a}}$, R.H.M. de Groot ${ }^{\mathrm{c}, \mathrm{d}}$, R.W.L. Godschalk ${ }^{\mathrm{e}}$, \\ T.R. Southwood ${ }^{f}$, L. Smits ${ }^{g}$, N. Stratakis ${ }^{a, h}$, I.S.M. van de Wurff ${ }^{d}$, M.P. Zeegers ${ }^{a, c}$ \\ ${ }^{a}$ Department of Complex Genetics, Care and Public Health Research Institute, Maastricht University, 6200 MD, Maastricht, the Netherlands \\ ${ }^{\mathrm{b}}$ Institute of Applied Health Research, College of Medical and Dental Sciences, University of Birmingham, B15 2TT, Birmingham, UK \\ ${ }^{\mathrm{c}}$ Department of Complex Genetics, School for Nutrition and Translational Research in Metabolism, Maastricht University, 6200 MD, Maastricht, the Netherlands \\ ${ }^{\mathrm{d}}$ Welten Institute, Research Centre for Learning, Teaching, and Technology, Open University of the Netherlands, 6419 AT, Heerlen, the Netherlands \\ ${ }^{\mathrm{e}}$ Department of Pharmacology and Toxicology, School for Nutrition and Translational Research in Metabolism, Maastricht University, 6200 MD, Maastricht, the \\ Netherlands \\ ${ }^{\mathrm{f}}$ Institute of Child Health, University of Birmingham, B15 2TT, Birmingham, UK \\ ${ }^{\mathrm{g}}$ Department of Epidemiology, Care and Public Health Research Institute, Maastricht University, 6200 MD, Maastricht, the Netherlands \\ ${ }^{\mathrm{h}}$ Department of Preventive Medicine, Keck School of Medicine, University of Southern California, 90032, Los Angeles, USA
}

\section{A R T I C L E I N F O}

\section{Keywords:}

Prenatal programming

Developmental origins of health and disease Biomarkers

Polyunsaturated fatty acids

Problem behaviours

Social competence

\begin{abstract}
A B S T R A C T
Background: The prenatal exposure to maternal n- 6 and n-3 polyunsaturated fatty acids (PUFAs) might influence the development of social competence and internalizing and externalizing behaviours of the child, because of the numerous functions of PUFAs within the nervous system.

Methods: To analyse the association of selected maternal PUFAs (i.e., AA, EPA, DHA, total n-6, total n-3, and the n-6:n-3 ratio) measured during gestation with childhood social competence and problem behaviours, we examined 311 mother-child pairs from the Maastricht Essential Fatty Acid Birth (MEFAB) cohort. For each woman, PUFA-specific changes in relative concentrations were calculated by identifying the best-fitting curve of PUFA concentration by linear splines of gestational age. The associations of changes in maternal PUFAs in early and late pregnancy with childhood social competence, total problems, internalizing and externalizing behaviours, measured with the Child Behaviour Checklist 4/18 at age 7, were investigated with linear regression analyses adjusted for maternal and children's socio-demographic characteristics.

Results: In late gestation (i.e., from gestational week 30), an increase in AA was associated with higher social competence, while a decrease in total n-6 was associated with lower externalizing behaviours. No other significant associations were found.

Discussion: In this prospective study, increasing maternal AA and decreasing total n-6 were associated with improved social competence and externalizing behaviours, respectively, in 7-year old children. Nonetheless, the clinical significance of the identified associations is modest and further investigations are warranted to clarify the relationship between maternal AA and total n-6 during pregnancy and childhood social and behavioural development.
\end{abstract}

\section{Introduction}

Social competence is a multidimensional trait that includes the ability to interact with other people and manage different situations
[1]. Lower social competence is tightly related to internalizing (which includes extreme emotional reactions) and externalizing (which includes aggressive reactions) problem behaviours $[2,3]$, with emotionally distressed or aggressive children often being socially incompetent

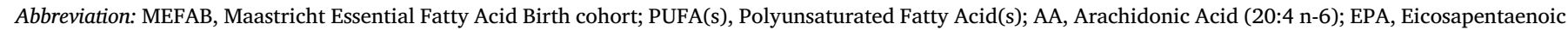

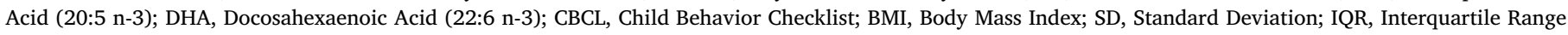

* Corresponding author: Department of Complex Genetics, Care and Public Health Research Institute (School CAPHRI), Maastricht University, 6200 MD Maastricht, the Netherlands.

E-mail address: e.tore@maastrichtuniversity.nl (E.C. Tore). 
[4]. Both a lack of social competence and the presence of problem behaviours can have deleterious effects for the individual and the society, including a higher risk for psychiatric disorders and delinquency during adulthood [4-7]. Since an early identification of at-risk children might have substantial public health benefits, the perinatal environment, which might play a central role in shaping future behaviour [8], is receiving increasing attention.

Inadequate amounts of polyunsaturated fatty acids (PUFAs) during brain development may be associated with a suboptimal neurological performance. Specifically, the long-chain PUFAs (i.e., the n- 6 arachidonic acid, AA, and the n-3 eicosapentaenoic acid, EPA, and docosahexaenoic acid, DHA) are involved in processes necessary for brain development, including neuronal maturation and synaptic functions [9-15].

Because of the brain growth spurt in late gestation [16], most studies have analysed PUFA concentrations in the umbilical cord blood in an attempt to examine their associations with child problem behaviours [17-19]. Published results are, however, inconclusive, and the association of these fatty acids at birth with childhood behaviour is still unclear. Besides, even early-pregnancy PUFA availabilities might have an influence on the foetus' developing brain [20,21], since all neuronal structures form during the embryonic stage [16]. Nonetheless, earlyand mid-pregnancy maternal long-chain PUFAs in relation to problem behaviours and emotional problems at 6 years of age have been analysed only in one cohort [22,23]. Higher maternal plasma DHA concentrations in mid-pregnancy were associated with less emotional problems [22]; however, only a marginally significant association was observed when analysing DHA concentrations in early pregnancy [23]. Moreover, mid-pregnancy AA concentrations were positively associated with problem behaviours in the same population of children [22].

Contrarily to problem behaviours, the development of social competence has been studied less extensively: to our knowledge, no studies have been published examining the potential association of prenatal maternal PUFA status with social competence development in humans. Nonetheless, an animal study reported that piglets whose mothers were fed a DHA-rich diet during pregnancy showed more social activities and played more, compared to piglets whose mothers were fed an oleic acidrich diet [24]. Since pigs are considered good models for human nutrition and neurobiology [25], we hypothesised that higher maternal PUFAs during pregnancy might be associated with improved social competence in children as well.

The Maastricht Essential Fatty Acids Birth (MEFAB) cohort has collected extensive data on maternal PUFA concentrations during all trimesters and at delivery, which can be used as a proxy for the child's prenatal fatty acids exposure [26]. Consequently, this birth cohort offers the unique opportunity of examining in a longitudinal fashion the association of maternal plasma phospholipids over the course of pregnancy with child development.

The main objective of the present study was to analyse the association between the change in selected maternal PUFAs (i.e., AA, EPA, DHA, total $n-6$, total $n-3$ concentrations and $n-6: n-3$ ratio) during pregnancy with childhood social competence and problem behaviours measured with the Child Behaviour Checklist. Given the previously highlighted functions that these PUFAs have in children's neurological development, we hypothesised that each of them would be independently associated with social competence and problem behaviours. Previous studies showed that all PUFAs' relative concentrations during pregnancy undergo a physiological reduction, which could be modulated by maternal dietary PUFA intakes [27]. We, therefore, hypothesised that a smaller reduction in AA, EPA, DHA and total n-3 concentrations during pregnancy would be associated with improved childhood social competence and problem behaviours. Considering the complementarity between total n-3 and total n-6, we hypothesised that a reduction in total $n-6$ or $n-6: n-3$ ratio would be associated with better outcomes in children.

Contrarily to the previously published literature, in which single measurements of maternal PUFAs during pregnancy were used to predict childhood outcomes, in the present study we calculated the subjectand PUFA-specific change in relative concentrations by modelling subsequent measurements of maternal PUFA concentrations in plasma phospholipids. We therefore obtained subject- and PUFA-specific variations in concentration in two gestational periods (i.e., early and late). This novel approach allows a greater control for random variations in PUFA concentrations and provides a more accurate representation of foetal exposures to maternal fatty acids [28].

\section{Materials and methods}

\subsection{Study population}

The MEFAB cohort is a prospective birth cohort established in 1989 in the southern part of the Netherlands. MEFAB's main aim was to analyse the variations in maternal PUFA concentrations during pregnancy and their correlations with infants' fatty-acid concentrations and with various birth outcomes. Details of the study population and the data collection have been previously reported [29]. Briefly, between 1989 and 1995, 1203 pregnant women were recruited. In this period, maternal blood samples and socio-demographic data were collected as described in Sections 2.2, 2.3 and 2.4 below. A follow-up study was conducted when the children were 7 years old (1997-2000). Seven hundred and fifty children were eligible, of whom 421 (56\%) eventually participated. Children were excluded from participation in this study if less than 2 maternal blood samples were collected over the course of pregnancy or at delivery, or if no information on child problem behaviours was obtained, resulting in 311 mother-child pairs included in the present analysis. The study was approved by the Medical Ethics Committee, University Hospital, Maastricht/ University of Maastricht, Netherlands.

The non-response analysis revealed that participating women had a lower body mass index (BMI) at study entry compared to non-participants (median: $22.85 \mathrm{~kg} / \mathrm{m}^{2}$, IQR: $21.48 ; 25.10$ in participants $v s$. $23.43 \mathrm{~kg} / \mathrm{m}^{2}$, IQR: $21.27 ; 26.18$ in non-participants; $p=0.024$ ). Furthermore, a higher birth weight of participating children compared to those non-participating $(3347.39 \mathrm{~g}, \mathrm{SD}=514.70 \mathrm{vs}$. $3197.42 \mathrm{~g}$, $\mathrm{SD}=579.92 ; p<0.001)$. However, no other significant differences were found in other sociodemographic characteristics, including gestational weight gain, smoking status, pregnancy outcomes (i.e., birth weight by gestational age) and parity. Furthermore, no differences were found in total $n-6$, total $n-3$ or the n-6:n-3 ratio between women included and excluded from the current study (table S1, Supplementary material). Hence, selection bias was not expected to be an issue.

\subsection{Maternal PUFAs}

Maternal blood samples were collected during clinic visits before week 16 of pregnancy (mean: 10.49; SD: 2.74 weeks), around week 22 $(21.99 \pm 1.32$ weeks), around week 32 (31.96 \pm 0.91 weeks), and at delivery (39.18 \pm 1.80 weeks) to measure the phospholipid fatty acids profile as previously described [30,31]. Briefly, maternal venous blood samples were collected into tubes containing ethylenediaminetetraacetic acid (EDTA) to prevent coagulation. Plasma was, then, separated from erythrocytes by centrifugation before being stored at $-80^{\circ} \mathrm{C}$ under nitrogen. A modified Folch extraction $[32,33]$ was used to prepare total lipid extracts from $100 \mu 1$ plasma samples after addition of $\mathrm{L}$ $\alpha$-Dinonadecanoyl lecithin as internal standard to calculate the absolute fatty acid amounts (mg/L). Aminopropyl-bonded phase columns were used to separate phospholipids from the total lipid extract. The fatty acid constituents of the phospholipids were transmethylated to the corresponding methylesters, which were separated and quantified on a nonpolar CP-Sil 5 CB column (Chrompack, Middelburg, The Netherlands). All analysed PUFA concentrations were expressed as weight percentages (weight of fatty acids measured against total fatty acids 
present; wt\%). For the purpose of the present analysis, plasma phospholipids were preferred over erythrocytes, because they are considered to be better indicators of recent PUFA intakes or mobilisation [30,34,35].

All assayed n-6 PUFAs and n-3 PUFA concentrations were summed up to calculate the total n- 6 and n-3 PUFAs, respectively. Furthermore, the total n-6 and the total n-3 were used to compute the n- $6: n-3$ ratio. More details regarding the specific PUFAs included can be found in table S2 (Supplementary materials). Measures of variation in the concentration of AA, EPA, DHA, total n-6, total n-3 and n-6:n-3 ratio during pregnancy were used as exposures in the main analysis (see Sections 2.5.2 and 2.5.3), given these PUFAs' hypothesised roles in foetal brain development [9-15,20] and previously hypothesised associations with childhood problem [17-19,22,23].

\subsection{Child behaviour checklist}

The Dutch version of the Child Behaviour Checklist (CBCL) 4/18 was used to assess children's social competence and problem behaviours as perceived by their parents [36-38]. The CBCL has demonstrated good psychometric properties, reliability and validity $[39,40]$. The social competence scale of the CBCL 4/18 consists of 20 items grouped into three subscales: social skills, activity engagement and school functioning (i.e. academic performance, and academic and other problems in school). Furthermore, three aspects of problem behaviours can be assessed through the CBCL: 1) internalizing problems, which consists of the social withdrawal, somatic complaints and anxiety/depression scales; 2) externalizing problems, which comprises the delinquent behaviour and aggressive behaviour scales; and 3) total problems, which is the sum of the internalizing and externalizing scales, together with additional syndrome sub-scales focused on social, thought, attention and sex problems. Elements of the social competence scale can be scored $0-1,0-2$ or $0-3$, with increasing scoring corresponding to higher competence, while each item of problem behaviours scales can be scored $0-2$, with higher scores corresponding to greater problem behaviours. To allow comparability between studies, raw scores are usually converted into age-standardised T-scores (with a mean of 50 and a standard deviation of 10). This study assessed the T-scores for the social competence, total problem, internalizing and externalizing scales. High social competence T-scores (i.e., over 40) denote a normal development, while for total problems, internalizing and externalizing behaviours higher T-scores (i.e., more than 63) indicate clinical levels of symptomatology.

\subsection{Covariates}

Information about maternal age, BMI, smoking during pregnancy (yes/no) and parity (primipara/multipara) was recorded by hospital staff at study entry. Data on child's sex and birth weight (in grams) were recorded by hospital staff at delivery. Gestational age at birth (in weeks) was calculated from the date of the last menstrual period. Data regarding breastfeeding (exclusive breastfeeding, bottle feeding, or combinations) were collected by means of questionnaires at follow-up. Due to a low number of mothers who reported to have exclusively breastfed their children $(n=21,9.68 \%)$, this category was merged to the combination category (i.e., breastfeeding and bottle-milk). Parents' level of education was categorised into low, middle or high; the highest category was chosen in case of discordance between parents [41]. Parents' employment status was categorised as: both parents working full-time, one working full-time while the other part-time, and both working part-time. None of the parents reported being unemployed. Children's weight and height were measured by research staff when children were 7 years old. At follow-up, parents of 191 children (61.41\%) gave informed consent for the assessment of their children's plasma PUFAs, which were measured following the same methodology used to assay maternal PUFAs.

\subsection{Statistical analysis}

All statistical analyses were done in Stata v.14 [42], with the level of statistical significance set at 0.05 .

\subsubsection{Descriptive statistics}

Maternal and children's characteristics are reported as mean and standard deviation (mean (SD)), median and interquartile range (median (IQR)) or number and percentage (n (\%)), as appropriate. Maternal PUFA concentrations at each measurement time-point are reported as mean (SD); to assess the differences between PUFA concentrations at different time-points, one-way analysis of variance (ANOVA) and Bonferroni's post hoc tests were used. PUFA-specific concentration changes in early and late pregnancy, calculated as explained in Section 2.5.2, are reported as mean (SD).

\subsubsection{PUFA-specific concentration changes during pregnancy}

Since maternal PUFA concentrations throughout pregnancy vary following non-linear patterns, we estimated the best-fitting curve of each fatty-acid concentration during gestation. To improve the prediction, all women with at least one PUFA measurement during pregnancy were included $(n=1285)$. First, we modelled PUFA concentrations throughout pregnancy as a function of gestational age using linear splines $[28,43]$. For each PUFA, we aimed at identifying a set of knots that allowed the construction of the best-fitting curve. We selected one knot per curve that was, then, used to define two periods during pregnancy (i.e., early and late). The identified splines were used in mixed-effect linear regression models with a random intercept for mother and a random slope, allowing for individual variations of maternal fatty acids. Subject- and PUFA-specific slopes, calculated considering both the fixed and the random portions of the regressions, were then extracted and used as main exposures in subsequent linear regression analyses. These slopes represent the change in PUFA concentration in specific periods of pregnancy, as defined by the previously identified knots.

\subsubsection{Linear regression analyses}

The associations of change in maternal fatty-acid concentrations during pregnancy with social competence and problem behaviours were analysed by means of linear regression analyses. Two models were constructed. First, we tested the crude, non-adjusted associations; then, we adjusted for the following a priori selected variables based on previous studies of perinatal PUFAs and child problem behaviours [18,19,22,23]: maternal age, smoking during pregnancy, maternal BMI at study entry, parental educational level, parental employment status, parity, breastfeeding, child's sex and age at assessment. Furthermore, the measured PUFA concentration at the beginning of pregnancy was introduced into the model as a proxy for maternal habitual PUFA status. The interaction of maternal PUFA with child's sex was also examined. Since relative PUFA concentrations were used, no additional controlling for other fatty acids was applied.

For ease of interpretation of statistically significant results, we used the MIMRGNS [44] command in Stata to predict children's scores in social competence and problem behaviours at the 5th, 25th, 50th, 75th and 95th percentiles of maternal PUFAs' change during late pregnancy, while keeping constant all other variables - including the same PUFA's variation in early pregnancy.

To reduce bias due to missing values, multiple imputation of missing covariate data was performed. Fifty imputed datasets were generated using the multiple imputation of chained equation (MICE) method [45]. To increase the precision of the imputation, all outcomes, exposures, and confounders were included in the imputation model, together with additional auxiliary variables- i.e., weight gain during pregnancy, pregnancy outcomes, day-care attending, delivery mode, gestational age, birth weight, postpartum depression, child's BMI and waist-to-hip ratio at follow-up, and child's PUFAs at follow-up. The appropriateness 
Table 1

Population's characteristics.

\begin{tabular}{lll}
\hline Maternal characteristics & $\mathrm{n}$ & Mean (SD), Median (IQR) or n (\%) \\
\hline Age at delivery (years) & 311 & $29.70(3.92)$ \\
Smoking during pregnancy (\% yes) & 308 & $68(22.08 \%)$ \\
Level of education & 215 & \\
High & & $78(36.28 \%)$ \\
Middle & & $92(42.79 \%)$ \\
Low & 219 & $45(20.93 \%)$ \\
Employment status & & $12(5.48 \%)$ \\
Both full-time & & $119(54.34 \%)$ \\
One full-time, one part-time & & $88(40.18 \%)$ \\
Both part-time & 311 & $221(71.06 \%)$ \\
Parity (\% primiparas) & 294 & $22.85(21.48 ; 25.10)$ \\
BMI at study entry & 218 & $99(45.41 \%)$ \\
Breastfeeding (\% yes) & $\mathbf{n}$ & Mean (SD), Median (IQR) or n (\%) \\
Children's characteristics & 311 & $163(52.41 \%)$ \\
Sex (\% males) & 311 & $39.18(1.80)$ \\
Gestational age (weeks) & 217 & $7.30(0.26)$ \\
Age at follow-up (years) & 310 & $3347.39(514.70)$ \\
Birth weight (g) & 216 & $15.24(14.42 ; 16.44)$ \\
BMI (at 7 years) & & \\
\hline & &
\end{tabular}

of the imputation model was confirmed by comparing the distribution of imputed values with that of observed values [46]. Furthermore, complete-case analyses were performed by including only participants with no missing values on any confounding factor.

Sensitivity analyses were performed to assess the robustness of the results: 1) birth weight and gestational age, 2) maternal postpartum depression, and 3) child's BMI and PUFAs at follow up were included in the adjusted the model separately to evaluate their effect on the coefficients for maternal PUFAs.

In a secondary analysis, we examined the associations between each PUFA, measured at 10, 22, 32 and 40 weeks of gestation, with social competence and problem behaviours to allow for an easier comparison with previously published studies. All linear regressions were controlled for the set of a priori confounding factors identified for the main analysis.

\section{Results}

The study population's characteristics are reported in table 1 . On average, mothers were 29.70 (3.92) years old and were predominantly non-smokers and primiparas. Children's mean T-scores were: 44.71 (8.62) for social competence, 50.70 (10.97) for total problems, 51.84 (10.34) for internalizing problems and 50.91 (10.42) for externalizing problems.

Mean and standard deviation values for each PUFA concentration are presented in table 2. Mean PUFA concentrations varied over the course of pregnancy, with higher values found in the first or second periods except for the $n-6: n-3$ ratio. The mean, linear changes in PUFA concentrations in early and late pregnancy are shown in table 3. Higher
Table 3

Change in concentrations in maternal PUFAs throughout pregnancy.

\begin{tabular}{|c|c|c|}
\hline \multirow[t]{3}{*}{ PUFAs } & \multicolumn{2}{|c|}{ Change in concentrations (wt $\% /$ week) } \\
\hline & Early $^{\mathrm{a}}$ & Late $^{\mathrm{a}}$ \\
\hline & Mean (SD) & \\
\hline AA & $-0.07(0.03)$ & $0.03(0.06)$ \\
\hline EPA & $-0.01(0.02)$ & $-0.00(0.00)$ \\
\hline DHA & $0.02(0.03)$ & $-0.02(0.01)$ \\
\hline Total n-6 & $-0.03(0.04)$ & $-0.07(0.03)$ \\
\hline Total n-3 & $0.06(0.08)$ & $-0.02(0.01)$ \\
\hline$n-6: n-3$ & $-0.07(0.08)$ & $0.02(0.02)$ \\
\hline
\end{tabular}

Note: a) cut-off points for different PUFAs derived from the identified bestfitting linear splines. For AA and Total n-6, the "late" pregnancy starts at week 30, for EPA at week 22, for DHA at week 20, and for Total n-3 and the n-6:n-3 ratio at week 10 .

absolute values indicate a greater change in concentration, compared to no change. The definition of early and late depends on the specific PUFA's variation throughout pregnancy, and, therefore, on the selection of the best knots for the linear splines' construction. For AA and total n6 , late pregnancy would start at week 30, for EPA at week 22, for DHA at week 20, and for total n-3 and the n-6:n-3 ratio at week 10 .

Tables 4-7 present the results of the linear regressions subdivided by CBCL scale. In the unadjusted model, increasing DHA concentration in early pregnancy was marginally significantly associated with social competence $(\beta=-37.67 ; 95 \%$ C.I.: $-75.53,0.19 ; p=0.051)$. In the adjusted model, an increase in AA and in total n- 6 in late pregnancy was statistically significantly associated with social competence (AA: $\beta=25.13$; 95\% C.I.: 3.40, 46.85; $p=0.024$ ) and externalizing behaviours (total n-6: $\beta=83.05$; 95\% C.I.: $18.19,147.90 ; p=0.012$ ), respectively (table 4). No other statistically significant associations were found (tables 4-7).

An increase in maternal plasma AA in late pregnancy $(0.15 \mathrm{wt}$ $\% /$ week $v$ s. $-0.07 \mathrm{wt} \% /$ week, which correspond to the 95th and 5th percentiles, respectively) is expected to result in 5.50-point higher social competence $\mathrm{T}$-score, after controlling for previously identified confounders (Fig. 1). Furthermore, a larger decrease in maternal plasma total $\mathrm{n}-6$ in late pregnancy $(-0.12 \mathrm{wt} \% /$ week $v$ s. $-0.03 \mathrm{wt} \% /$ week, corresponding to the 5th and 95th percentiles, respectively) is expected to result in lower externalizing behaviours, with a drop of 8.20 points compared to a smaller decrease in maternal plasma total n-6 concentration (Fig. 2).

When analysing the association between maternal AA and social competence, there was some evidence of an interaction between AA in late pregnancy and child's sex $(p=0.033)$; however, after stratification by child's sex, both associations were not statistically significant (results not shown). Sensitivity analyses showed no changes in the coefficients after the inclusion of several possible mediators to the adjusted model (data not shown, available upon request).

Tables S3-S6 in the Supplementary material show the results of the

Table 2

Mean maternal gestational PUFA concentrations throughout pregnancy.

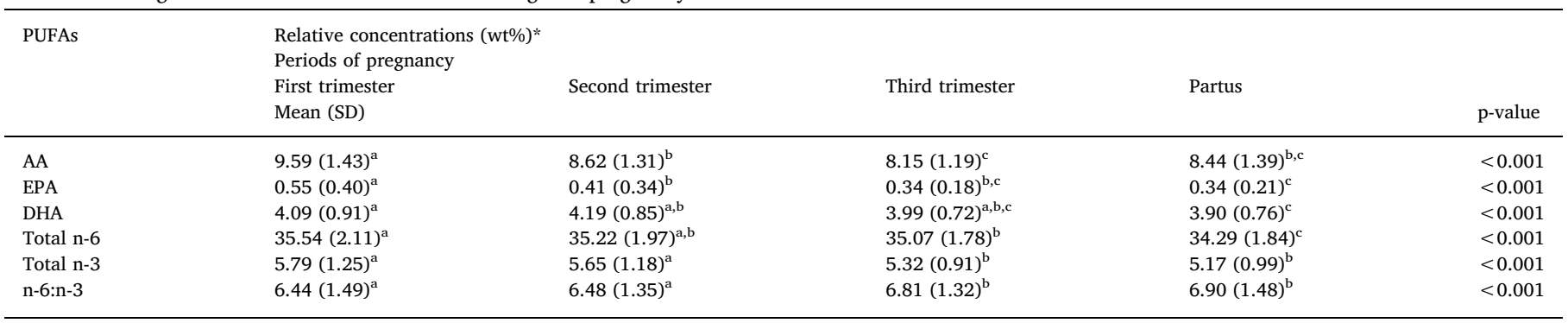

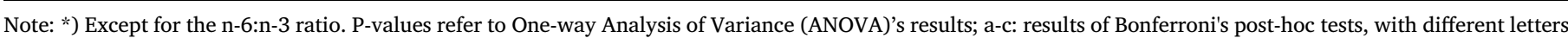
representing a statistically significant difference $(p<0.05)$ between PUFA concentrations in different periods of pregnancy. 
Table 4

Associations of maternal gestational PUFAs with social competence, presented by gestational period.

\begin{tabular}{|c|c|c|c|c|}
\hline PUFAs & $\begin{array}{l}\text { Early pregnancy } \\
\text { Beta ( } 95 \% \text { C.I.) } \\
\text { Unadjusted }\end{array}$ & Adjusted $^{\mathrm{b}}$ & $\begin{array}{l}\text { Late pregnancy } \\
\text { Beta }(95 \% \text { C.I.) } \\
\text { Unadjusted }\end{array}$ & Adjusted $^{\mathrm{b}}$ \\
\hline $\mathrm{AA}$ & $\begin{array}{l}-27.95 \\
(-57.37,1.48)\end{array}$ & $\begin{array}{l}-19.21 \\
(-70.18,31.76)\end{array}$ & $\begin{array}{l}8.11 \\
(-7.23,23.44)\end{array}$ & $\begin{array}{l}25.13^{*} \\
(3.40,46.85)\end{array}$ \\
\hline EPA & $\begin{array}{l}-14.60 \\
(-64.22,35.01)\end{array}$ & $\begin{array}{l}67.98 \\
(-315.03,450.99)\end{array}$ & $\begin{array}{l}-21.28 \\
(-238.37,195.81)\end{array}$ & $\begin{array}{l}-125.91 \\
(-929.76,677.95)\end{array}$ \\
\hline DHA & $\begin{array}{l}-37.67 \\
(-75.53,0.19)^{\S}\end{array}$ & $\begin{array}{l}-14.13 \\
(-77.87,49.61)\end{array}$ & $\begin{array}{l}28.72 \\
(-47.92,105.37)\end{array}$ & $\begin{array}{l}81.77 \\
(-29.52,193.06)\end{array}$ \\
\hline Total n-6 & $\begin{array}{l}20.89 \\
(-11.50,53.27)\end{array}$ & $\begin{array}{l}23.65 \\
(-17.54,64.84)\end{array}$ & $\begin{array}{l}-14.74 \\
(-52.41,22.94)\end{array}$ & $\begin{array}{l}-15.63 \\
(-68.97,37.71)\end{array}$ \\
\hline Total n-3 & $\begin{array}{l}-2.50 \\
(-15.44,10.45)\end{array}$ & $\begin{array}{l}-2.88 \\
(-22.68,16.92)\end{array}$ & $\begin{array}{l}-28.96 \\
(-99.42,41.49)\end{array}$ & $\begin{array}{l}108.36 \\
(-48.59,265.32)\end{array}$ \\
\hline$n-6: n-3$ & $\begin{array}{l}4.99 \\
(-7.82,17.80)\end{array}$ & $\begin{array}{l}10.63 \\
(-7.70,28.96)\end{array}$ & $\begin{array}{l}7.26 \\
(-48.09,62.61)\end{array}$ & $\begin{array}{l}-52.33 \\
(-133.35,28.69)\end{array}$ \\
\hline
\end{tabular}

Note: Imputed dataset analysis, $n=311$.

a Cut-off points for different PUFAs derived from the identified best-fitting linear splines. For AA and Total n-6, the "late" pregnancy starts at week 30, for EPA at week 22, for DHA at week 20, and for Total n-3 and the n-6:n-3 ratio at week 10;.

b Adjusted for: mother's age, smoking during pregnancy, maternal BMI at study entry, parental education, parental employment status, breastfeeding, parity, child's sex and age at follow up.

§ $p \leq 0.06$;

* $p \leq 0.05$.

secondary analyses. Statistically significant, positive associations were observed between AA at 40 weeks of gestation and EPA at 32 weeks, respectively, and social competence (AA: $\beta=1.63$; 95\% C.I.: 0.49,2.77; $p=0.005$. $\quad$ EPA: $\beta=8.04 ; \quad 95 \%$ C.I.: $0.31, \quad 15.77 ; p=0.041$ ). Furthermore, statistically significant positive associations were found between AA at 10 and 40 weeks of gestation and internalizing behaviours (week 10: $\beta=1.33$; 95\% C.I.: 0.01 , $2.65 ; p=0.049$. week 40: $\beta=1.47$; 95\% C.I.: $0.15,2.80 ; p=0.030$ ), and between total $n-6$ at 40 weeks and externalizing behaviours $(\beta=1.13 ; 95 \%$ C.I.:0.05, 2.20; $p=0.040$ ). Finally, EPA in week 10 was statistically significantly, negatively associated with externalizing behaviours $(\beta=-4.17 ; 95 \%$ C.I.: $-8.05,-0.03 ; p=0.035)$. No other statistically significant associations were found.

\section{Discussion and conclusions}

To our knowledge, this is the first study to investigate the association of maternal PUFAs during pregnancy with childhood social competence and problem behaviours, using a novel approach to evaluate the change in PUFA concentrations throughout pregnancy. Present results showed that a larger increase in maternal AA during late pregnancy (i.e., from week 30 of gestation) was associated with a modest increase in social competence at 7 years of age. Similarly, a larger reduction in total $n-6$ in the same period was associated with a small decrease in externalizing behaviours at 7 years of age. In the sensitivity analyses, additional control for possible mediators of the main associations did not alter the results. Besides, changes in other PUFAs during pregnancy were not statistically significantly associated with scores on the social competence or problem behaviour scales.

When reflecting on the clinical relevance of the identified associations, it should be considered that the predicted scores of the social competence and externalizing behaviour scales fall within the normaldevelopment range. Nonetheless, children of women who reported a small decrease in AA concentration in late pregnancy were more likely to present a level of social competence close to the clinical level. If future studies will confirm these results, it should be recommended to monitor the variation in maternal AA and total n-6 in late pregnancy. In fact, given that similar variations in PUFA concentrations were observed in pregnant women from five different countries [27], changes in maternal metabolism that occurs during pregnancy [47] might be

Table 5

Associations of maternal gestational PUFAs with total problems, presented by gestational period.

\begin{tabular}{|c|c|c|c|c|}
\hline PUFAs & $\begin{array}{l}\text { Early pregnancy }{ }^{\mathrm{a}} \\
\text { Beta (95\% C.I.) } \\
\text { Unadjusted }\end{array}$ & Adjusted $^{\mathrm{b}}$ & $\begin{array}{l}\text { Late pregnancy } \\
\text { Beta ( } 95 \% \text { C.I.) } \\
\text { Unadjusted }\end{array}$ & Adjusted $^{\mathrm{b}}$ \\
\hline AA & $\begin{array}{l}-3.11 \\
(-40.68,34.47)\end{array}$ & $\begin{array}{l}-8.10 \\
(-74.29,58.09)\end{array}$ & $\begin{array}{l}2.80 \\
(-16.79,22.39)\end{array}$ & $\begin{array}{l}7.59 \\
(-20.51,35.69)\end{array}$ \\
\hline EPA & $\begin{array}{l}-5.84 \\
(-68.64,56.96)\end{array}$ & $\begin{array}{l}322.59 \\
(-168.09,813.27)\end{array}$ & $\begin{array}{l}30.96 \\
(-243.83,305.74)\end{array}$ & $\begin{array}{l}561.34 \\
(-470.54,1593.21)\end{array}$ \\
\hline DHA & $\begin{array}{l}-12.35 \\
(-60.49,35.78)\end{array}$ & $\begin{array}{l}-24.16 \\
(-106.17,57.86)\end{array}$ & $\begin{array}{l}-24.81 \\
(-122.25,72.64)\end{array}$ & $\begin{array}{l}10.76 \\
(-130.84,152.36)\end{array}$ \\
\hline Total n-6 & $\begin{array}{l}3.57 \\
(-37.36,44.50)\end{array}$ & $\begin{array}{l}4.89 \\
(-47.20,56.97)\end{array}$ & $\begin{array}{l}27.74 \\
(-19.87,75.36)\end{array}$ & $\begin{array}{l}51.54 \\
(-15.70,118.77)\end{array}$ \\
\hline Total n-3 & $\begin{array}{l}-10.71 \\
(-27.06,5.64)\end{array}$ & $\begin{array}{l}-4.53 \\
(-29.81,20.76)\end{array}$ & $\begin{array}{l}-19.37 \\
(-108.35,69.61)\end{array}$ & $\begin{array}{l}-41.18 \\
(-241.59,159.23)\end{array}$ \\
\hline$n-6: n-3$ & $\begin{array}{l}11.13 \\
(-5.03,27.29)\end{array}$ & $\begin{array}{l}7.64 \\
(-15.58,30.86)\end{array}$ & $\begin{array}{l}13.90 \\
(-55.93,83.73)\end{array}$ & $\begin{array}{l}12.67 \\
(-90.52,115.87)\end{array}$ \\
\hline
\end{tabular}

Note: Imputed dataset analysis, $n=311$.

a Cut-off points for different PUFAs derived from the identified best-fitting linear splines. For AA and Total n-6, the "late" pregnancy starts at week 30, for EPA at week 22, for DHA at week 20, and for Total n-3 and the n-6:n-3 ratio at week 10;.

b Adjusted for: mother's age, smoking during pregnancy, maternal BMI at study entry, parental education, parental employment status, breastfeeding, parity, child's sex and age at follow up. $\S p \leq 0.06$; ${ }^{*} p \leq 0.05$. 
Table 6

Associations of maternal gestational PUFAs with internalizing problems, presented by gestational period.

\begin{tabular}{|c|c|c|c|c|}
\hline PUFAs & $\begin{array}{l}\text { Early pregnancy } \\
\text { Beta ( } 95 \% \text { C.I.) } \\
\text { Unadjusted }\end{array}$ & Adjusted $^{\mathrm{b}}$ & $\begin{array}{l}\text { Late pregnancy } \\
\text { Beta }(95 \% \text { C.I.) } \\
\text { Unadjusted }\end{array}$ & Adjusted $^{\mathrm{b}}$ \\
\hline $\mathrm{AA}$ & $\begin{array}{l}-3.90 \\
(-38.90,31.10)\end{array}$ & $\begin{array}{l}-30.31 \\
(-91.46,30.84)\end{array}$ & $\begin{array}{l}0.72 \\
(-17.52,18.96)\end{array}$ & $\begin{array}{l}8.99 \\
(-16.84,34.82)\end{array}$ \\
\hline EPA & $\begin{array}{l}-27.90 \\
(-86.28,30.48)\end{array}$ & $\begin{array}{l}129.43 \\
(-328.52,587.38)\end{array}$ & $\begin{array}{l}20.87 \\
(-234.58,276.31)\end{array}$ & $\begin{array}{l}147.55 \\
(-812.19,1107.29)\end{array}$ \\
\hline DHA & $\begin{array}{l}-11.21 \\
(-56.08,33.66)\end{array}$ & $\begin{array}{l}-55.33 \\
(-131.08,20.43)\end{array}$ & $\begin{array}{l}3.10 \\
(-87.74,93.94)\end{array}$ & $\begin{array}{l}16.20 \\
(-115.02,147.42)\end{array}$ \\
\hline Total n-6 & $\begin{array}{l}-5.21 \\
(-43.42,33.00)\end{array}$ & $\begin{array}{l}-2.93 \\
(-51.34,45.49)\end{array}$ & $\begin{array}{l}19.14 \\
(-25.31,63.59)\end{array}$ & $\begin{array}{l}35.71 \\
(-26.69,98.11)\end{array}$ \\
\hline Total n-3 & $\begin{array}{l}-9.65 \\
(-24.88,5.59)\end{array}$ & $\begin{array}{l}-11.29 \\
(-34.68,12.09)\end{array}$ & $\begin{array}{l}-6.68 \\
(-89.61,76.24)\end{array}$ & $\begin{array}{l}-24.06 \\
(-209.64,161.53)\end{array}$ \\
\hline$n-6: n-3$ & $\begin{array}{l}9.35 \\
(-5.72,24.43)\end{array}$ & $\begin{array}{l}14.59 \\
(-6.89,36.07)\end{array}$ & $\begin{array}{l}-0.87 \\
(-66.02,64.27)\end{array}$ & $\begin{array}{l}7.78 \\
(-87.76,103.32)\end{array}$ \\
\hline
\end{tabular}

Note: Imputed dataset analysis, $n=311$.

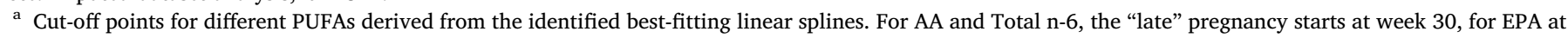
week 22, for DHA at week 20, and for Total n-3 and the n-6:n-3 ratio at week 10;.

b Adjusted for: mother's age, smoking during pregnancy, maternal BMI at study entry, parental education, parental employment status, breastfeeding, parity, child's sex and age at follow up. $\S p \leq 0.06 ;{ }^{*} p \leq 0.05$.

largely responsible for the variation in PUFA concentrations. However, dietary intake of PUFA-rich foods or supplements before and during pregnancy can have an impact on maternal and foetal PUFA levels [27], potentially preventing a suboptimal child development.

Despite AA being part of the n- 6 PUFA family, from the present results an increase in maternal AA concentration appears beneficial for an optimal social competence development, while a reduction in total $\mathrm{n}-6$ seems more beneficial for externalizing behaviours. It could be hypothesised that high concentrations of linoleic acid (LA), which constitutes the vast majority of total n-6 PUFAs, might have a deleterious effect on foetal brain development. However, when examining the associations between the change in LA concentration during pregnancy and childhood social competence and problem behaviours, we did not find any statistically significant result (results not shown).

On the other hand, AA, the most abundant long-chain PUFA of the human brain [12], is considered a crucial enhancer of neurological development [48]: it affects neuronal excitability and synaptic transmission [48], and is probably involved in nerve growth and synaptogenesis, processes in which it might play a crucial role by regulating the maturation of synaptic endings [49]. Furthermore, it is particularly represented in brain regions responsible for sensorimotor integration and various language-implicated processes - i.e., pre- and post-central cortices, basal ganglia, hippocampus and thalamus [12,50-52]. An altered brain AA metabolism has been related to numerous neurological processes and psychiatric disorders, including schizophrenia, epilepsy and mood disorders [53]. Considering that social competence is related with sensory processing [54] and language development [55], it seems worthwhile to further investigate the development of social competence and the possible role of AA on this process, despite the modest clinical significance of the reported association.

Although no studies analysing the association between maternal PUFAs during pregnancy and childhood social competence have been published, a few have explored the development of problem behaviours, reporting inconclusive results [17-19,22,23]. Studies examining the association between PUFA concentrations in the umbilical cord blood and childhood problem behaviours reported either no statistically significant association [17], a decrease in total problems and emotional problems for every unit increase in DHA and AA, respectively [19], or a reduction in internalizing problems for every unit increase in DHA in children fed exclusively with artificial formula, but not in those

Table 7

Associations of maternal gestational PUFAs with externalizing problems, presented by gestational period.

\begin{tabular}{|c|c|c|c|c|}
\hline PUFAs & $\begin{array}{l}\text { Early pregnancy } \\
\text { Beta (95\% C.I.) } \\
\text { Unadjusted }\end{array}$ & Adjusted $^{\mathrm{b}}$ & $\begin{array}{l}\text { Late pregnancy } \\
\text { Beta (95\% C.I.) } \\
\text { Unadjusted }\end{array}$ & Adjusted $^{\mathrm{b}}$ \\
\hline AA & $\begin{array}{l}3.18 \\
(-32.83,39.19)\end{array}$ & $\begin{array}{l}-7.98 \\
(-72.40,56.44)\end{array}$ & $\begin{array}{l}6.92 \\
(-11.85,25.68)\end{array}$ & $\begin{array}{l}9.06 \\
(-18.09,36.21)\end{array}$ \\
\hline EPA & $\begin{array}{l}19.88 \\
(-40.29,80.05)\end{array}$ & $\begin{array}{l}291.86 \\
(-186.45,770.17)\end{array}$ & $\begin{array}{l}-13.85 \\
(-277.12,249.41)\end{array}$ & $\begin{array}{l}348.91 \\
(-655.19,1353.00)\end{array}$ \\
\hline DHA & $\begin{array}{l}-6.56 \\
(-52.59,39.48)\end{array}$ & $\begin{array}{l}-8.26 \\
(-88.02,71.51)\end{array}$ & $\begin{array}{l}-59.42 \\
(-152.62,33.78)\end{array}$ & $\begin{array}{l}-39.00 \\
(-176.09,98.08)\end{array}$ \\
\hline Total n-6 & $\begin{array}{l}-0.92 \\
(-39.85,38.01)\end{array}$ & $\begin{array}{l}-11.05 \\
(-60.98,38.89)\end{array}$ & $\begin{array}{l}51.47 \\
(6.18,96.76)\end{array}$ & $\begin{array}{l}82.87^{*} \\
(18.21,147.54)\end{array}$ \\
\hline Total n-3 & $\begin{array}{l}-7.23 \\
(-22.91,8.45)\end{array}$ & $\begin{array}{l}5.79 \\
(-18.76,30.34)\end{array}$ & $\begin{array}{l}-35.99 \\
(-121.34,49.35)\end{array}$ & $\begin{array}{l}-94.98 \\
(-289.18,99.22)\end{array}$ \\
\hline$n-6: n-3$ & $\begin{array}{l}6.41 \\
(-9.08,21.90)\end{array}$ & $\begin{array}{l}-3.97 \\
(-26.45,18.51)\end{array}$ & $\begin{array}{l}38.38 \\
(-28.54,105.30)\end{array}$ & $\begin{array}{l}34.80 \\
(-64.92,134.52)\end{array}$ \\
\hline
\end{tabular}

Note: Imputed dataset analysis, $n=311$.

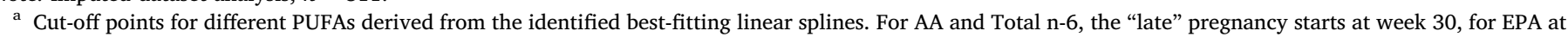
week 22, for DHA at week 20, and for Total n-3 and the n-6:n-3 ratio at week 10;.

b Adjusted for: mother's age, smoking during pregnancy, maternal BMI at study entry, parental education, parental employment status, breastfeeding, parity, child's sex and age at follow up.

$\S: p \leq 0.06$;

* $p \leq 0.05$. 


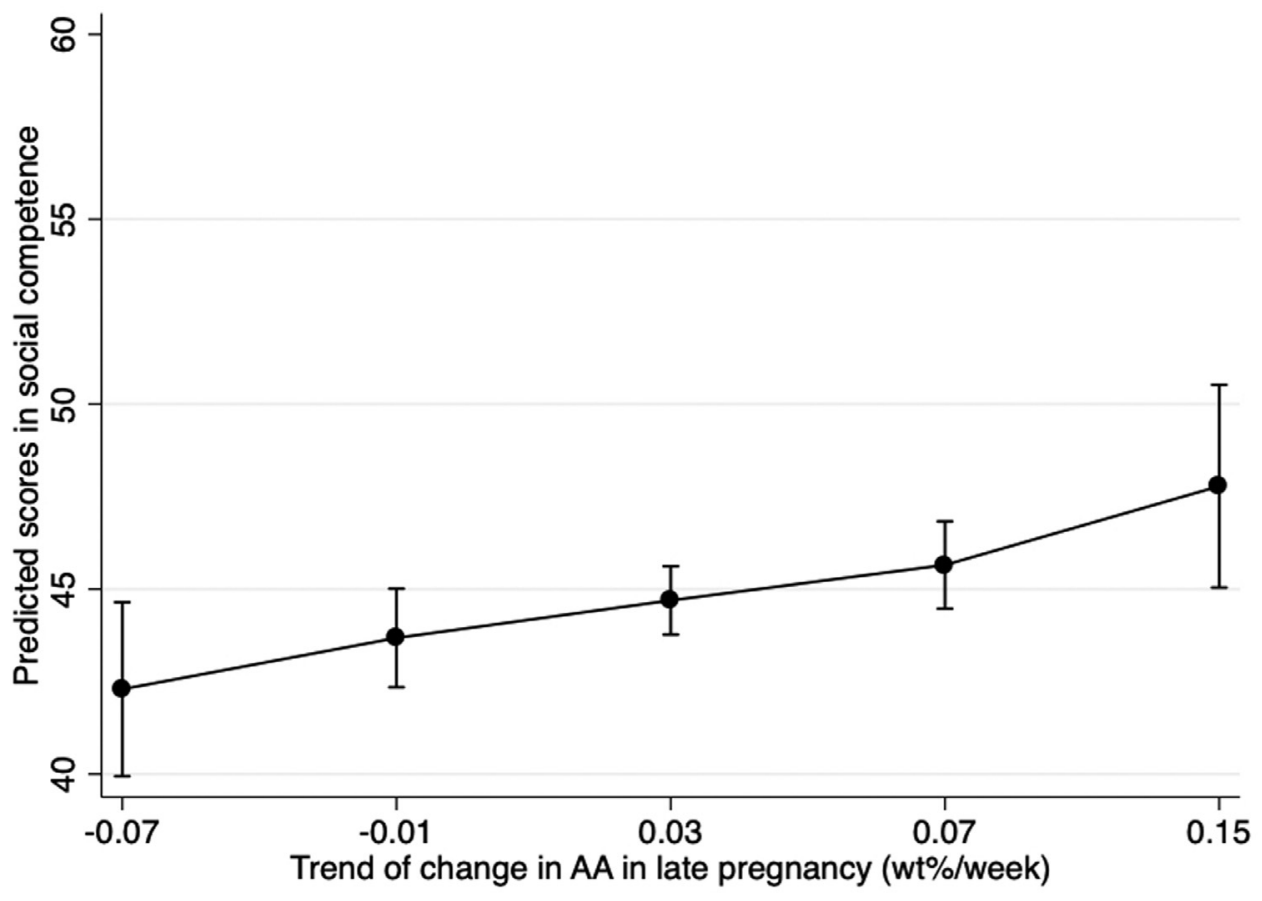

Fig. 1. Predicted social competence score at the 5th, 25th, 50th, 75th and 95th percentiles of change in maternal AA concentration in late pregnancy.

Note: the $\mathrm{x}$ - axis represents the change in AA in late gestation in the present population of pregnant women. Presented values correspond to the 5 th $(-0.07 \mathrm{wt} \% /$ week), 25th $(-0.01 \mathrm{wt}$ $\%$ /week), 50th (0.03 wt\%/week), 75th (0.07 wt $\% /$ week) and 95th (0.15 wt\%/week) percentiles. . breastfed [18]. In the Generation R Study, maternal DHA and n-3:n-6 ratio in mid-pregnancy were negatively associated with child emotional problems, while a positive association between maternal AA in midpregnancy and total problems was observed [22]. However, when considering maternal PUFAs in early-pregnancy, only a marginally significant, negative association was observed between DHA and emotional symptoms in the same cohort [23]. These results can be compared to those of the present study's secondary linear regression analysis, in which positive associations between AA and internalizing behaviours and total n-6 PUFAs and externalizing behaviours were observed. Furthermore, EPA was negatively associated with externalizing behaviours and positively associated with social competence. However, considering only one PUFA measurement at a time does not constitute an appropriate representation of foetal exposure during gestation. Furthermore, this approach can lead to biased results due to uncontrolled extreme values, which could potentially represent a shift in other PUFAs if relative concentrations are used.

The main strength of the present study is, therefore, the analytical approach used, which accounts for previously published studies' shortcomings. Instead of presenting a sequence of linear regressions using the four fatty-acid measurements as separate predictors, in the main analysis we constructed PUFA-specific concentration curves throughout gestation. In doing so, we assumed no significant deviations from the predicted values between measurements. However, since we noticed a general trend in PUFA concentrations among participants, we are confident this method provides an adequate representation of the

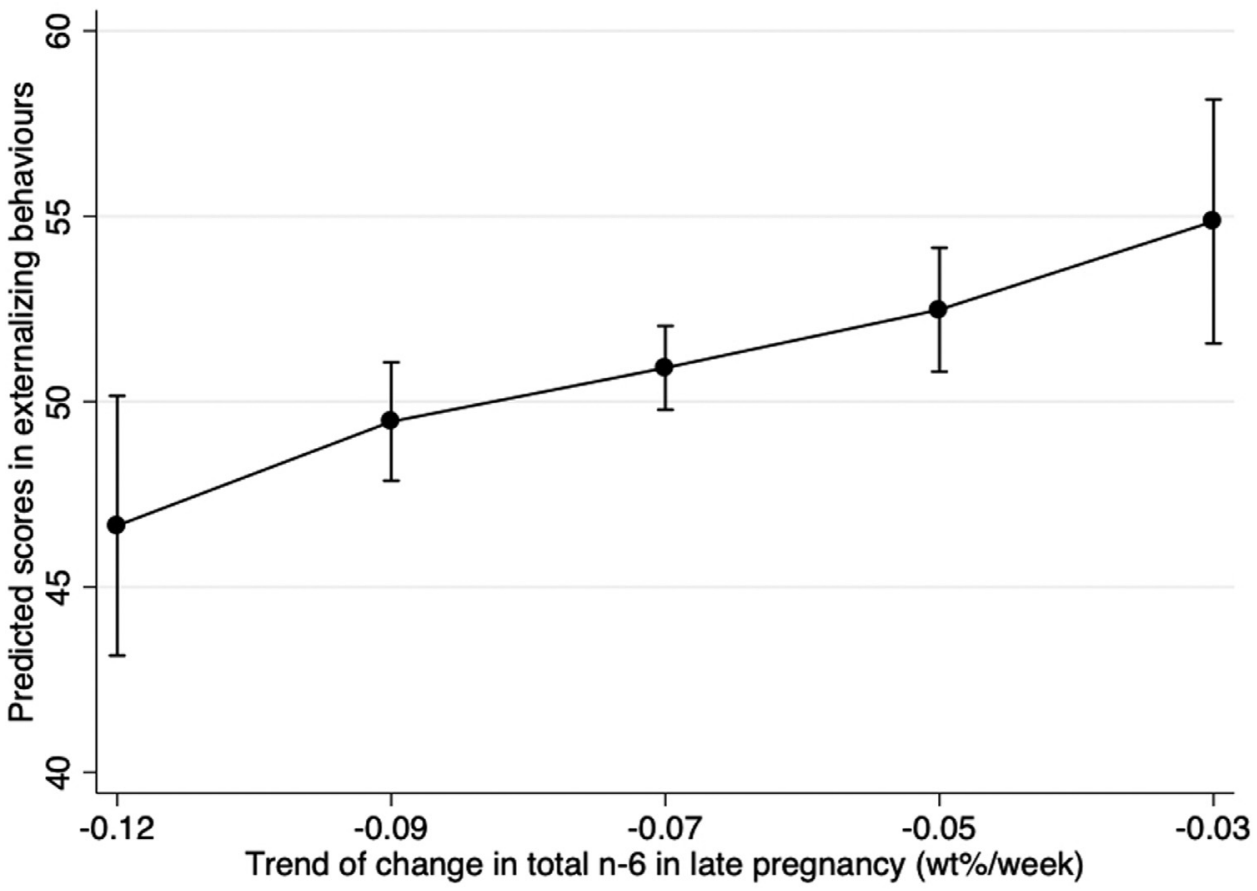

Fig. 2. Predicted externalizing behaviour score at the 5th, 25th, 50th, 75th and 95th percentiles of change in maternal total $n-6$ concentration in late pregnancy.

Note: the $\mathrm{x}$ - axis represents the change in total $\mathrm{n}-6$ in late gestation in the present population of pregnant women. Presented values correspond to the 5th $(-0.12 \mathrm{wt} \% /$ week $)$, 25th ( $-0.09 \mathrm{wt} \% /$ week), 50th $(-0.07 \mathrm{wt} \% /$ week $)$, 75th $(-0.05 \mathrm{wt} \% /$ week $)$ and 95th $(-0.03 \mathrm{wt}$ $\% /$ week) percentiles. 
change in maternal PUFA concentrations during pregnancy. Compared to any sequence of linear regression analyses, here the temporal variation of exposures is taken into account, while extreme values tend to be smoothed.

Another strength of this study is represented by the use of biomarkers to assess gestational PUFA concentrations. This is certainly a more reliable method to assess foetal exposure to PUFAs compared to questionnaires assessing maternal intake of specific food items. Apart from being subject to a wide range of biases potentially affecting the results, questionnaires only allow for estimations of PUFA intakes, and cannot consider the rise in their concentrations during pregnancy resulting from the mobilisation of fatty acids stored in maternal adipose tissues [56]. Furthermore, most studies assessing the association between maternal diet and childhood problem behaviours focused only on maternal fish and seafood intake [57-60] - with the clear intent of estimating prenatal exposures to n-3 PUFAs, whose concentrations is considerably higher in fish and seafood products compared to other food items. The possible association of n-6 PUFAs, including AA, with social competence and problem behaviours has been, however, largely neglected.

The results of the present study and the large number of analyses performed might raise concerns about multiple testing. Yet, in our opinion there is no need to control for multiple tests, given the high intercorrelations within the exposures and the outcomes [61], and the pre-defined hypotheses for every association tested [62]. Furthermore, the two associations between AA with social competence and total n-6 with externalizing behaviours were statistically significant in every sensitivity analysis performed, with estimates of the same magnitude and in the same direction. Finally, given the novelty of the present analysis, in our opinion increasing the chance of false negative results might unnecessarily prevent future investigations $[61,62]$.

This study's findings should be interpreted with caution because of a few limitations. In spite of the large number of respondents at baseline, the final study population was affected by a high loss to follow-up rate, which might have introduced biases. Nonetheless, most sociodemographic characteristics were similar among participants and nonparticipants, including maternal PUFAs during pregnancy. Furthermore, although we controlled for numerous sociodemographic characteristics, residual confounding is still possible. Specifically, we were not able to control for two potential postnatal influences on the development of social competence and problem behaviours: parenting practices and parental psychopathology. In fact, although we attempted to account for maternal psychopathology by controlling for maternal postpartum depression in one of the sensitivity analyses, we must note that postpartum depression represents only a limited facet of the complex pattern of parental psychopathology.

In conclusion, this study suggests that a rise in maternal AA and a reduction in total n-6 in late pregnancy might be associated with a small improvement in childhood social competence and externalizing behaviours, respectively, at 7 years of age. In contrast, changes in other PUFAs during pregnancy were not associated with social competence or problem behaviour scale in school-age children. Future studies are warranted to further investigate the association between maternal n- 6 PUFAs and childhood social competence and problem behaviours, preferably accounting for parental psychopathology and parenting practices.

\section{Acknowledgements}

Authors wish to thank Professor Emeritus Gerard Hornstra, who made the MEFAB study possible, all families for participating in this study, and the Master student Ayodele Fela Thomis for her preliminary work.

\section{Sources of support}

The MEFAB cohort was financially supported by the Dutch organization for Scientific Research(NWO, grant number 90462 186) and by the University Hospital of Maastricht, The Netherlands (Profilerings Fonds). The blinded fatty acid analyses were financed by Royal Numico, Wageningen, The Netherlands.

\section{Declaration of conflict of interest}

Authors declare no conflict of interest.

\section{Supplementary materials}

Supplementary material associated with this article can be found, in the online version, at doi:10.1016/j.plefa.2019.04.002.

\section{References}

[1] P.M.S. Nugent, Social Competence, PsychologyDictionary.org, 2013.

[2] Q. Chen, Y. Jiang, Social competence and behavior problems in Chinese preschoolers, Early Educ. Develop. 13 (2002) 171-186.

[3] S. Vahedi, F. Farrokhi, F. Farajian, Social competence and behavior problems in preschool children, Iran. J. Psychiatry 7 (2012) 126-134.

[4] M. Semrud-Clikeman, Social Competence in Children, in: Social competence in Children, Springer, New York, 2007.

[5] C.R. Petty, J.F. Rosenbaum, D.R. Hirshfeld-Becker, A. Henin, S. Hubley, S. LaCasse, S.V. Faraone, J. Biederman, The child behavior checklist broad-band scales predict subsequent psychopathology: a 5-year follow-up, J. Anxiety Disord. 22 (2008) $532-539$.

[6] J. Reef, I. van Meurs, F.C. Verhulst, J. van der Ende, Children's problems predict adults' DSM-IV disorders across 24 years, J. Am. Acad. Child Adolesc. Psychiatry 49 (2010) 1117-1124.

[7] J. Stevenson, Association between behaviour at age 3 years and adult criminality, Br. J. Psychiatry 179 (2001) 197-202.

[8] V.S. Knopik, J.M. Neiderhiser, E. de Geus, D. Boomsma, The importance of the prenatal environment in behavioral genetics: introduction to special issue, Behav. Genet. 46 (2016) 281-285.

[9] D. Cao, K. Kevala, J. Kim, H.-S. Moon, S.B. Jun, D. Lovinger, H.-Y. Kim, Docosahexaenoic acid promotes hippocampal neuronal development and synaptic function, J. Neurochem. 111 (2009) 510-521.

[10] G.l. Champeil-Potokar, M. Hennebelle, A.e. Latour, S. Vancassel, I. Denis, Docosahexaenoic acid (DHA) prevents corticosterone-induced changes in astrocyte morphology and function, J. Neurochem. 136 (2016) 1155-1167.

[11] P.E. Lonergan, D.S. Martin, D.F. Horrobin, M.A. Lynch, Neuroprotective effect of eicosapentaenoic acid in hippocampus of rats exposed to gamma-irradiation, J. Biol. Chem. 277 (2002) 20804-20811.

[12] J. Zhao, H.A. Weiler, Arachidonic Acid, Brain Development, Implications in the Offspring of Diabetic Pregnant Women. in: G.G. Dumancas, B.S. Murdianti, E.A. Lucas (Eds.), Arachidonic Acid : Dietary Sources \& General Functions, Nova Science, Hauppauge, N.Y., 2013.

[13] K. Gharami, M. Das, S. Das, Essential role of docosahexaenoic acid towards development of a smarter brain, Neurochem. Int. 89 (2015) 51-62.

[14] M. Hadders-Algra, Prenatal and early postnatal supplementation with long-chain polyunsaturated fatty acids: neurodevelopmental considerations, Am. J. Clin. Nutr. 94 (2011) 1874S-1879S.

[15] R. Uauy, P. Mena, C. Rojas, Essential fatty acids in early life: structural and functional role, Proc. Nutr. Soc. 59 (2000) 3-15.

[16] F.H. Gilles, M.D. Nelson, Brain Growth, in: The Developing Human Brain : Growth and Adversities, Mac Keith Press, London, 2012, pp. 14-15.

[17] C. de Jong, H.K. Kikkert, J. Seggers, G. Boehm, T. Decsi, M. Hadders-Algra, Neonatal fatty acid status and neurodevelopmental outcome at 9 years, Early Hum. Dev. 91 (2015) 587-591.

[18] L. Krabbendam, E. Bakker, G. Hornstra, J. van Os, Relationship between DHA status at birth and child problem behaviour at 7 years of age, Prostaglandins, Leukotrienes Essen. Fatty Acids 76 (2007) 29-34.

[19] G. Kohlboeck, C. Glaser, C. Tiesler, H. Demmelmair, M. Standl, M. Romanos, B. Koletzko, I. Lehmann, J. Heinrich, L.I.S. Group, Effect of fatty acid status in cord blood serum on children's behavioral difficulties at $10 \mathrm{y}$ of age: results from the LISAplus Study, Am. J. Clin. Nutr. 94 (2011) 1592-1599.

[20] P. Coti Bertrand, J.R. O'Kusky, S.M. Innis, Maternal dietary (n-3) fatty acid deficiency alters neurogenesis in the embryonic rat brain, J. Nutr. 136 (2006) 1570-1575.

[21] N. Sakayori, T. Kikkawa, H. Tokuda, E. Kiryu, K. Yoshizaki, H. Kawashima, T. Yamada, H. Arai, J.X. Kang, H. Katagiri, H. Shibata, S.M. Innis, M. Arita, N. Osumi, Maternal dietary imbalance between omega- 6 and omega-3 polyunsaturated fatty acids impairs neocortical development via epoxy metabolites, Stem Cells 34 (2016) 470-482.

[22] J.C. Steenweg-De Graaff, M.G. Basten, J. Rijlaarsdam, V.W. Jaddoe, H. Tiemeier, F.C. Verhulst, S.J. Roza, A. Hofman, H. Demmelmair, B. Koletzko, Maternal LC- 
PUFA status during pregnancy and child problem behavior: the Generation R Study, World Rev. Nutr. Diet. 114 (2016) 75-76.

[23] E.M. Loomans, B.R.H. Van den Bergh, M. Schelling, T.G.M. Vrijkotte, M. van Eijsden, Maternal long-chain polyunsaturated fatty acid status during early pregnancy and children's risk of problem behavior at age 5-6 years, J. Pediatr. 164 (2014) 762-768.

[24] C. Clouard, A.S. Souza, W.J.J. Gerrits, R. Hovenier, Maternal fish oil supplementation affects the social behavior, brain fatty acid profile, and sickness response of piglets, J. Nutr. 145 (2015) 2176-2184.

[25] C. Clouard, M.C. Meunier-Salaün, D. Val-Laillet, Food preferences and aversions in human health and nutrition: how can pigs help the biomedical research? Anim. Int. J. Anim. Biosci. 6 (2012) 118-136.

[26] M.D.M. Al, A.C. van Houwelingen, G. Hornstra, Long-chain polyunsaturated fatty acids, pregnancy, and pregnancy outcome, Am. J. Clin. Nutr. 71 (2000) 285-291.

[27] S.J. Otto, A. Houwelingen, M. Antal, A. Manninen, K. Godfrey, P. López-Jaramillo, G. Hornstra, Maternal and neonatal essential fatty acid status in phospholipids: an international comparative study, Eur. J. Clin. Nutr. 51 (1997) 232-242.

[28] Y.-H. Chen, K.K. Ferguson, J.D. Meeker, T.F. McElrath, B. Mukherjee, Statistical methods for modeling repeated measures of maternal environmental exposure biomarkers during pregnancy in association with preterm birth, Environ. Health 14 (2015).

[29] I.S.M. van de Wurff, R.H.M. Groot, N. Stratakis, M. Gielen, G. Hornstra, M. Zeegers, Maastricht essential fatty acid birth cohort, Lipid Technol. 27 (2015) 59-62.

[30] M.D. Al, A.C. van Houwelingen, A.D. Kester, T.H. Hasaart, A.E. de Jong, G. Hornstra, Maternal essential fatty acid patterns during normal pregnancy and their relationship to the neonatal essential fatty acid status, Br. J. Nutr. 74 (1995) 55-68.

[31] M.D.M. Al, G. Hornstra, Y.T. van der Schouw, M.T.E.W. Bulstra-Ramakers, H.J. Huisjes, Biochemical EFA status of mothers and their neonates after normal pregnancy, Early Hum. Dev. 24 (1990) 239-248.

[32] J. Folch, M. Lees, G.H. Sloane Stanley, A simple method for the isolation and purification of total lipides from animal tissues, J. Biol. Chem. 226 (1957) 497-509.

[33] E.B. Hoving, G. Jansen, M. Volmer, J.J. Vandoormaal, F.A.J. Muskiet, Profiling of plasma-cholesterol ester and triglyceride fatty-acids as their methyl-esters by capillary gas-chromatography, preceded by a rapid aminopropyl-silica column chromatographic-separation of lipid classes, J. Chromatograp. Biomed. Applica. 434 (1988) 395-409.

[34] L. Serra-Majem, M. Nissensohn, N.C. Overby, K. Fekete, Dietary methods and biomarkers of omega 3 fatty acids: a systematic review, Br. J. Nutr. 107 (2012) S64-S76.

[35] A.B. Courville, M.R. Keplinger, M.P. Judge, C.J. Lammi-Keefe, Plasma Or Red Blood Cell Phospholipids Can Be Used to Assess Docosahexaenoic Acid Status in Women During Pregnancy 29 Nutrition research, New York, N.Y., 2009, pp. 151-155.

[36] T.M. Achenbach, C.S. Edelbrock, Manual For the Child Behavior Checklist and Revised Child Behavior Profile, T.M. Achenbach, Burlington, VT, 1983.

[37] F.C. Verhulst, J. Van Der Ende, J.M. Koot, Handleiding Voor De CBCL/4-18, Afdeling Kinder- en Jeugdpsychiatrie, Sophia Kinderziekenhuis/Academisch Ziekenhuis Rotterdam/Erasmus Universiteit Rotterdam, Rotterdam, 1996.

[38] T.M. Achenbach, T.M. Ruffle, The Child Behavior Checklist and related forms for assessing behavioral/emotional problems and competencies, Pediatr. Rev. 21 (2000) 265-271.

[39] H.M. Koot, F.C. Verhulst, Prediction of children's referral to mental health and special education services from earlier adjustment, J. Child Psychol. Psychiatry 33 (1992) 717-729.

[40] F.C. Verhulst, H.M. Koot, J.V.d. Ende, Differential predictive value of parents' and teachers' reports of children's problem behaviors: a longitudinal study, J. Abnorm. Child Psychol. 22 (1994) 531-546.

[41] P.S. de Vries, M. Gielen, D. Rizopoulos, P. Rump, R. Godschalk, G. Hornstra,
M.P. Zeegers, Association between polyunsaturated fatty acid concentrations in maternal plasma phospholipids during pregnancy and offspring adiposity at age 7: the MEFAB cohort, Prostaglandins Leukot. Essent. Fatty Acids 91 (2014) 81-85.

[42] StataCorp, Stata Statistical Software: Release 14, in, College Station, StataCorp LP, TX, 2015.

[43] K. Tilling, C. Macdonald-Wallis, D.A. Lawlor, R.A. Hughes, L.D. Howe, Modelling childhood growth using fractional polynomials and linear splines, Ann. Nutri. Metabo 65 (2014) 129-138.

[44] D. Klein, MIMRGNS: Stata module to run margins after mi estimate, Statistical Software Components S457795, Boston Coll. Depart. Econ. (2014).

[45] I.R. White, P. Royston, A.M. Wood, Multiple imputation using chained equations: issues and guidance for practice, Stat. Med. 30 (2011) 377-399.

[46] W. Eddings, Y. Marchenko, Diagnostics for multiple imputation in Stata, Stata J. 12 (2012) 353-367.

[47] E. Herrera, Implications of dietary fatty acids during pregnancy on placental, fetal and postnatal development-a review, Placenta 23 (2002) 9-19.

[48] H. Tallima, R. El Ridi, Arachidonic acid: physiological roles and potential health benefits - A review, J. Adv. Res. 11 (2017) 33-41.

[49] L.O. Kurlak, T.J. Stephenson, Plausible explanations for effects of long chain polyunsaturated fatty acids (LCPUFA) on neonates, Arch, Disea. Childhood Fetal Neonatal Ed. 80 (1999) F148.

[50] G.-Y. Diau, A.T. Hsieh, E.A. Sarkadi-Nagy, V. Wijendran, P.W. Nathanielsz, J.T. Brenna, The Influence of Long Chain Polyunsaturate Supplementation On Docosahexaenoic Acid and Arachidonic Acid in Baboon Neonate Central Nervous System, BMC Medicine, 2005, pp. 1-12.

[51] S.C. Berens, J.S. Horst, C.M. Bird, Cross-situational learning is supported by propose-but-verify hypothesis testing, Curr. Biol. 28 (2018) 1132-1136.

[52] A. Zenon, E. Olivier, Contribution of the basal ganglia to spoken language: is speech production like the other motor skills? Behav. Brain Sci. 37 (2014) 577-604.

[53] F. Bosetti, Arachidonic acid metabolism in brain physiology and pathology: lessons from genetically altered mouse models, J. Neurochem. 102 (2007) 577-586.

[54] C. Hilton, K. Graver, P. LaVesser, Relationship between social competence and sensory processing in children with high functioning autism spectrum disorders, Res. Autism Spect. Disord. 1 (2007) 164-173.

[55] P.C. McCabe, P.J. Meller, The relationship between language and social competence: how language impairment affects social growth, Psychol. Schools 41 (2004) 313-321.

[56] L. Lauritzen, S.E. Carlson, Maternal fatty acid status during pregnancy and lactation and relation to newborn and infant status, Mater. Child Nutr. 7 (2011) 41-58.

[57] J.R. Hibbeln, J.M. Davis, C. Steer, P. Emmett, I. Rogers, C. Williams, J. Golding, Maternal seafood consumption in pregnancy and neurodevelopmental outcomes in childhood (ALSPAC study): an observational cohort study, Lancet North Am. Ed. 369 (2007) 578-585.

[58] S.K. Sagiv, S.W. Thurston, D.C. Bellinger, C. Amarasiriwardena, S.A. Korrick, Prenatal exposure to mercury and fish consumption during pregnancy and attention-deficit/hyperactivity disorder-related behavior in children, Arch. Pediatr. Adoles. Med. 166 (2012) 1123-1131.

[59] C.R. Gale, S.M. Robinson, K.M. Godfrey, C.M. Law, W. Schlotz, F.J. O'Callaghan, Oily fish intake during pregnancy - association with lower hyperactivity but not with higher full-scale IQ in offspring, J. Child Psychol. Psychiatry 49 (2008) 1061-1068.

[60] T.C. Borge, H. Aase, A.L. Brantsæter, G. Biele, The Importance of Maternal Diet Quality During Pregnancy On Cognitive and Behavioural Outcomes in children: a Systematic Review and Meta-Analysis, BMJ Open, 2017.

[61] K.J. Rothman, No Adjustments Are Needed for Multiple Comparisons, Epidemiology 1 (1990) 43-46.

[62] D.L. Streiner, G.R. Norman, Correction for Multiple Testing, Chest 140 (2011) $16-18$. 